Journal of English Language Teaching and Applied Linguistics

ISSN: 2707-756X

DOI: $10.32996 /$ jeltal

Journal Homepage: www.al-kindipublisher.com/index.php/jeltal

JELTAL

\title{
Transfer of Learning Outcomes from an English-for-Specific-Academic-Writing Course to Subject-Specific Courses
}

\author{
Dr. Kalthoum Kassab 8 (iD. \\ Lecturer, Department of English, Faculty of Arts and Humanities of Sousse, Sousse University, Tunisia \\ $\triangle$ Corresponding Author: Dr. Kalthoum Kassab, E-mail: kalthoum.kassab@gmail.com
}

\author{
ARTICLE INFORMATION \\ Received: May 07, 2021 \\ Accepted: June 25, 2021 \\ Volume: 3 \\ Issue: 7 \\ DOI: $10.32996 /$ jeltal.2021.3.7.4
}

\section{KEYWORDS}

ESAP, transfer of learning

outcomes, near transfer, far

transfer, specificity/generality

\section{ABSTRACT}

This study investigated the transfer of ten learning outcomes from an ESAP writing course to subject-specific courses. It was a longitudinal study carried over one academic year. It followed 40 undergraduate students of English under normal classroom conditions. A mixed-methods approach was used. It included analysis of students' written exams from four subjects, student semi-structured interviews, and a student questionnaire. Elements from Barnett and Ceci's (2002) transfer taxonomy were also used. They helped classify the targeted learning outcomes in terms of specificity/generality and helped distinguish between near and far transfer contexts. Results showed that the transfer of the ten learning outcomes to the near and far transfer contexts was affected by the specificity/generality of the learned skill in the first place. The learning outcomes that were classified as specific transferred more easily to both the near and far transfer contexts, while the more complex learning outcomes transferred in a constrained manner. The findings suggest that an ESAP writing course that is informed by teaching for transfer principles offers students a more authentic learning environment to hone their writing skills and to transfer these skills to other contexts. However, this transfer can be a very slow process.

\section{Introduction}

Leki and Carson (1997) state that "the goals of most English for academic purposes (EAP) writing classes are transcendent. That is, the usual purpose is to enable students to write better not for EAP writing classes but for academic purposes" ( $p$ 39). EAP writing classes are supposed to prepare students for the writing requirements of their academic disciplines. Students, in turn, are expected to transfer what they learn from their EAP writing courses to their subject-specific courses. Transfer of learning is indeed a central goal in EAP writing instruction. As Johns (1993) puts it, "one of the most important aspects of an EAP reading/writing class (or any ESL/EFL class) is the development of transfer of learning" (p. 283). In order to achieve this goal, it is important to design EAP writing courses that are based on a clear understanding of what academic writing is and on what students are expected to learn. However, identifying the kind of EAP writing instruction that can lead to learning transfer is still a major issue, and central to this issue is the question of specificity (Flowerdew \& Peacock, 2001; Hyland, 2002, 2006, 2016a). In other words, teachers have to decide whether to opt for what is generally referred to as English for General Academic Purposes (EGAP) or English for Specific Academic Purposes (ESAP).

EGAP refers to the teaching of the language forms that are assumed to be transferable across all disciplines. This is related to Bloor and Bloor's (1986) common core hypothesis which is based on the idea that there is an identifiable set of grammatical and lexical items that can be found in any linguistic register. The common core is not restricted to grammar and vocabulary. It also includes other general elements referred to as study skills that include note-taking, summarizing, paraphrasing, synthesizing, quoting, citing, and logical thinking, among others. According to Jordan (1997), students, whether native or non-native speakers, are required to develop these general study skills to a level that allows them to cope with the requirements of their academic subjects. Similarly, Spack (1988) considers such study skills as a prerequisite for academic success. ESAP, on the other hand, takes

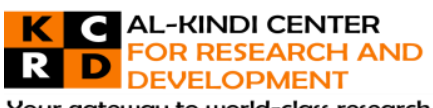

Your gateway to world-class research

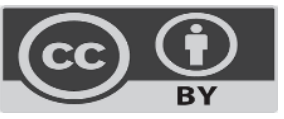

Published by Al-Kindi Center for Research and Development, United Kingdom. Copyright (c) the author(s). This open access article is distributed under a Creative Commons Attribution (CC-BY) 4.0 license 
a more complex dimension as it sees learning as a matter of "disciplinary socialization" (Hyland, 2006, p. 19) that focuses on the teaching of skills and practices that are specific to a particular discipline. Duff (2010) stresses the need for students to be socialized into the demands of academic discourse so that they can participate effectively in their new academic communities by using language appropriately. Disciplinary socialization is then a process that depends on students' understanding of the specificity of each academic discourse community.

The debate over which approach can help students develop the required academic skills is ongoing. The EGAP model has been criticized for dealing with the linguistic forms in total isolation of their contexts of use. Flowerdew and Peacock (2001), for example, describe the common core as "a formal system, divorced from meaning and use" (p. 17). In other words, it ignores the fact that each grammatical form carries many possible meanings depending on the context in which it is used. Hyland (2006) argues that if the meaning is to be incorporated in the common core, then there will be no escape from the notion of specific varieties and from the need to teach the language forms within these varieties. Furthermore, other researchers argue that the general principles that are assumed to be transferable across disciplines still need to be clearly defined. Johns (1988) notes that general skills such as note-taking, summary writing and general reading skills may reflect more differences than similarities across disciplines because the language required in each discipline is significantly influenced by the discipline, audience, and context. Therefore, even when using general skills such as these, students have to accommodate themselves in one way or another to each discipline that they encounter.

Studies that have investigated the kind of skills that students could transfer from their EAP writing course to their subject-specific courses in ESAP contexts from a learning transfer perspective are still rare. The present study aimed to investigate the learning outcomes that Tunisian students majoring in English could transfer from an ESAP writing course to their TEFL, literature and cultural studies courses over one academic year. The design of the ESAP writing course drew both from SFL genre theory and teaching for transfer theories. The study adopted a mixed-methods approach and aimed to answer two research questions:

1. What learning outcomes transferred and to which subjects did they transfer? (Researcher's identified transfer)

2. To what extent did students perceive that they had transferred the targeted learning outcomes to their other courses? (Students' identified transfer)

The next section of the paper reviews the learning transfer theories that informed the study. It also reviews the studies that investigated the transfer of learning outcomes in EAP contexts from a learning transfer perspective. The methodology section describes the research context, the participants, the research design, and the data analysis process. The results and discussion section discusses the major findings of the study in relation to the existing research. The paper concludes with a summary of the major findings, the pedagogical implications of the findings for EAP instruction, and the limitations that should be addressed in future research.

\section{Literature Review}

\subsection{Transfer of learning: Theoretical rationale 2.1.1 Defining transfer of learning}

Transfer of learning is generally defined as the application of prior learning to new situations or contexts. To Haskell (2001), "transfer refers to how previous learning influences current and future learning, and how past or current learning is applied or adapted to similar or novel situations" (p. 23). Researchers distinguish between two types of transfer: near transfer and far transfer. Near transfer occurs in situations or contexts which look very similar, and far transfer occurs in situations which look very different. Research on learning transfer within the cognitive school, which represents the traditional view of transfer, has provided important insights into the conditions that facilitate the transfer. For example, it is commonly accepted that conditions such as initial learning, level of abstraction, context, analogical transfer, and metacognition play an important role in promoting transfer (Bransford \& Schwartz, 1999). However, the research findings on learning transfer were generally disappointing. According to Detterman (1993), transfer research has failed to provide conclusive evidence for the existence of the most important kind of transfer: far transfer. What research could mostly show is near transfer which is produced by hints or, what Detterman calls, "tricks" that help learners identify the similarities between two problems. This means that near transfer is rather easy to identify since it depends on obvious and superficial similarities between the two situations. On the other hand, far transfer is much more difficult to identify because it "involves the ability to see underlying principles of similarity in situations which do not appear obviously alike" (Macaulay \& Cree, 1999, p. 184). A far transfer is not only the most difficult but also the most important to obtain (Detterman, 1993).

Failure to transfer has been linked to what researchers refer to as the problems of inert knowledge and local knowledge. According to Perkins and Salomon (1988), much of the knowledge that students acquire is "inert or passive" (p. 24). In other words, students may be able to display knowledge of what they have learned in multiple choice tests and quizzes; however, they 
do not transfer that knowledge to new contexts where it is intended and mostly needed. Larsen-Freeman (2013) points out the same problem of inert knowledge in the context of learning grammar, where students are able to show their grammar knowledge in standardized multiple-choice language tests, but they do not apply it in real communication. As for the problem of local knowledge, Perkins and Salomon (1988) argue that the knowledge that students acquire and the skills that they develop may be too specific to the contexts where they have been learned to be generalized and applied to novel contexts. For example, in the context of learning to write, Smit (2004) distinguishes between broadly-based and domain-specific and context-specific aspects of writing knowledge and ability. According to him, broadly-based aspects of writing can transfer from one writing context to another, while domain-specific and context-specific aspects do not because they are too local. For example, students who have learned and mastered writing only one specific genre, such as lab reports, does not mean that they have also mastered writing other kinds of genres, such as the grant proposal, whose organizational and linguistic features are different from those of lab reports.

\subsubsection{Adaptive transfer}

Approaches on how to address the failure of transfer present different perspectives. Some researchers (e.g., Lave \& Wenger, 1991; Greeno, 1997) have called for the need to look at transfer not only from a cognitive perspective but also from a sociocultural one. Unlike cognitivists who view learning transfer as a static phenomenon, socio-cultural theorists view transfer as an active and dynamic process. They seek adaptive transfer rather than the reuse of prior knowledge to new situations. For example, Lobato $(2003,2012)$ stresses the importance of adaptive transfer through her Actor-Oriented Transfer (AOT) model. This model shows how evidence for positive transfer could be reached when seen from a perspective that is different from that of the traditional transfer. For example, from an observer's point of view, transfer means that learners perform correctly on transfer tasks that the observer considers as similar to the initial learning tasks and that they are capable of drawing the same similarities as the observer. From an actor's point of view, however, the researcher does not seek to see whether learners have performed correctly but rather tries to understand the processes by which learners form connections between old and new situations even when their generalizations are incorrect (Lobato, 2003). Adopting this view of adapting transfer, DePalma and Ringer (2011) have called for the need to expand the discussions on adaptive transfer to EAP writing contexts. They argue that in order to understand how students use and, especially, "reshape" (p. 140) previously learned writing knowledge to fit new contexts, an expanded reconceptualization of writing transfer is needed in EAP contexts. Following this view of learning transfer, the present study also sought to explore learning transfer from both the researcher's point of view and the learners' point of view.

\subsubsection{Understanding mechanisms of transfer}

According to Perkins and Salomon (1988), the failure to transfer is not only linked to serious problems such as inert knowledge and local knowledge but also to the general misconception that transfer is an automatic process. They have also criticized the fact that the transfer literature tended to treat learning transfer as "a unitary phenomenon" (p. 119). That is, it did not attempt to distinguish between the two different mechanisms that may lead to transfer. Such routes include what the authors refer to as low road and high road transfer. Low road transfer is "the automatic triggering of well-practised routines in circumstances where there is a considerable perceptual similarity to the original learning context" (Perkins \& Salomon, 1988, p. 25). In other words, low road transfer is spontaneous and automatic because it involves the transfer of skills to contexts that share considerable similarities with the original contexts where they have been learned and mastered. It is a process that is based on two main factors: varied practice and automaticity (Perkins \& Salomon, 1988). Varied practice consists of learning a skill in a variety of contexts until it becomes quite automatic. Automaticity means that the person's behavior becomes "fast, effortless, and unlimited" (Perkins \& Salomon, 1989, p. 121). Low road transfer mostly relates to near transfer.

On the other hand, high road transfer "depends on the deliberate, mindful abstraction of skill or knowledge from one context for application in another" (Perkins \& Salomon, 1988, p. 25). According to Salomon and Perkins (1989), the key characteristic of high road transfer is a mindful abstraction which they define as "the deliberate, usually metacognitively guided and effortful, decontextualization of a principle, main idea, strategy, or procedure, which then becomes a candidate for transfer" (p. 126). Unlike low road transfer, which is almost an effortless process, high road transfer involves a great deal of complex reflective thinking since metacognition is assumed to play a major guiding role in this process. Moreover, it requires a state of alertness not only to the activities that learners are engaged in but also to the surrounding environments (Perkins \& Salomon, 1992). What also makes high road transfer a very complex process is that it requires a genuine understanding of the abstractions that learners make so that transfer can occur. High road transfer is generally related to the far transfer.

Both low road and high road transfer require a certain degree of mastery of initial learning as well as sufficient practice. For example, concerning low road transfer, fifty hours of practice or even a two-year course, according to Salomon and Perkins (1989), may not be sufficient to reach the required level of "near-automaticity". High road transfer, on the other hand, requires a teaching style that explicitly focuses on helping students learn how to engage in mindful abstraction. Thus, to Salomon and Perkins (1989), understanding mechanisms of transfer such as low road and the high road can lead to a better understanding of 
why transfer does not occur. More importantly, the authors strongly believe that such a model of transfer can encourage learning transfer on the condition that instruction focuses on teaching for transfer. They propose hugging as a strategy that encourages near transfer and bridging as a strategy that promotes far transfer. This teaching model was adopted in the present study. The low road/high road distinction was also used in order to make a distinction between the skills that tend to transfer along the low road and those that tend to transfer along the high road (James, 2014).

\subsubsection{Learning transfer dimensions}

Barnett and Ceci (2002) argue that specifying the relevant dimensions along which transfer occurs can lead to evidence for transfer. They developed a taxonomy that helps distinguish between near transfer and far transfer. This taxonomy is based on two main factors: content (what transferred) and context (transfer distance). Barnett and Ceci (2002) suggest three dimensions for content: learned skill, performance change, and memory demands. The learned skill dimension concerns the specificitygenerality of the learned skill. That is, whether it involves a specific procedure or a general skill. Applied to L2 writing, for example, a specific procedure refers to superficial features of writing such as knowledge of the structure of the English fiveparagraph essay (introduction, body, conclusion), whereas a general principle involves a much deeper level of understanding such as topic development, unity, coherence, audience awareness, and expressing criticality through discourse markers. This means that specific procedures and general principles may not transfer in the same way. James (2014) was the first who employed Barnett and Ceci's (2002) transfer taxonomy in EAP contexts, and he noted that specific procedures might transfer along the low road while general principles may transfer along the high road. Thus, classifying learning outcomes in terms of specificity-generality can give a clearer picture of the kind of transfer that may occur, that is, near transfer or far transfer. The performance change dimension refers to whether an improvement in the students' performance is expected, to the speed of the student's work, and to the approach that the students adopt to do their work. Finally, memory demands refer to whether transfer occurs spontaneously or is a result of hints and instructions (Barnett \& Ceci, 2002).

The context of transfer includes six dimensions: knowledge domain, physical context, temporal context, functional context, social context, and modality. Knowledge domain refers to the subject to which the skill is expected to transfer, for example, from a writing course to a history course. In this context, transfer is considered near or far depending on the similarities that the two subjects share in terms of content and skills. The physical context refers to whether the teaching and transfer tasks are carried in the same place and by the same teacher. Temporal context relates to the time that separates teaching and testing. The functional context defines the function that the learned skill serves (e.g., an activity involving getting a grade). The social context refers to whether the activity is done individually, in pairs, or in groups. Finally, modality relates to the type of the task, for example, a multiple-choice task versus an essay task. For Barnett and Ceci (2002), a transfer task does not have to meet the requirements of far transfer on all nine dimensions. Following this, the dimensions that were of interest in the present study included the learned skill and memory demands for the content of transfer and the knowledge domain, the physical context, the temporal context, and the modality for the context of transfer.

\subsection{Previous studies on learning transfer in EAP contexts}

To date, very few studies have investigated the transfer of learning outcomes from EAP writing courses to subject-specific courses. Moreover, studies which have drawn on transfer concepts such as adaptive transfer (DePalma \& Ringer, 2011), low road vs. high road transfer (Perkins \& Salomon, 1988), and near vs. far transfer (Barnett \& Ceci's, 2002) are still rare. In a study involving 30 ESL students enrolled in an EGAP writing course in a US university, James (2009) investigated whether learning outcomes from an EGAP writing course transfer to a writing task that is very different from the kind of writing done in the writing course but very similar to the text-responsible kind of writing required in content courses. The study was designed to take account for Perkins and Salomon's (1988) notions of high road transfer by asking students in interviews what they tried to transfer and of low road transfer by examining students' writing for evidence of learning transfer. James (2009) found that the difference between the writing task and the kind of writing done in the ESL writing course seemed to have impeded learning transfer. James also found that learning transfer was constrained with all the learning outcomes that were related to content and organization and not with those of language use, leading to the conclusion that learning outcomes related to language use tend to transfer more easily than learning outcomes related to content and organization.

In a subsequent study, James (2010a) found that while learning transfer occurred across disciplines, though to varying degrees, the transfer of learning outcomes between categories was somehow different from that found in the previous study (James, 2009). For example, in James' (2010a) study, the transfer of the learning outcomes related to organization was the most frequent, followed by language use and content. More importantly, transfer varied within categories themselves. For example, the language use category included not only the learning outcome that transferred the most (avoiding fused sentences) but also the learning outcome that transferred the least (using past perfect accurately). According to James (2010a), this may indicate that the transfer of learning outcomes may depend on the nature of the learning outcome itself and on whether the transfer is conscious (high road) or unconscious (low road). Zarei and Rahimi (2014) adapted James' (2010a) study in an EGAP writing course. The 
authors also found that the identified transfer varied across disciplines and across learning outcomes. In addition, unlike James' (2009) study which showed that language use tended to transfer the most, Zarei and Rahimi's (2014) findings revealed that learning outcomes associated with organization (use of temporal transitions) were the most frequent. James (2009, 2010a) and Zarei and Rahimi (2014) called for the need to conduct studies in ESAP contexts to see how much transfer can occur in comparison to EGAP contexts.

Shrestha's (2017) study is one of the very few studies that have investigated learning transfer in ESAP contexts. The study was conducted at an open and distance learning university in the United Kingdom. Drawing on socio-cultural theories of learning and SFL genre theories, Shrestha (2017) investigated the impact of dynamic assessment on students' ability to transfer conceptual knowledge and generic features of business genres such as case studies to their business courses. The study targeted far transfer because the case study assignment in the business studies course differed from the writing tasks in the EAP course in some ways. Shrestha (2017) found that dynamic assessment may promote transfer. The three participants in this study seemed to be able to transfer genre features and conceptual knowledge to their business studies course, although they were not equally successful. For two participants, the transfer of conceptual knowledge of business studies concepts was not as successful as that of genre features. Shrestha (2017) attributed this to the fact that the development of writing skills and conceptual knowledge is a long process that may require more support, motivation, and commitment. Hill et al. (2020) conducted a study in an ESAP context which was more grounded in learning transfer theories than Shrestha's (2017) study. Hill et al. (2020) investigated whether learning outcomes transferred from the engineering ESAP course to the students' writing in both the engineering ESAP course and the engineering-specific courses. The engineering ESAP course lasted only one semester, but the researchers tracked the student participants for one year in order to investigate the extent to which the transfer of the targeted learning outcomes was sustained. Hill et al. (2020) used only two elements of Barnett and Ceci's (2002) transfer taxonomy: the learned skill dimension for transfer content and the knowledge domain for transfer context. Concerning the specificity-generality of the learned skills, three learning outcomes were classified as general and five as specific. As for the knowledge domain dimension, near transfer was expected because the targeted transfer context - engineering courses - shared many similarities with the engineering ESAP course. Hill et al. (2020) found that most of the learning outcomes transferred within the ESAP course. On the other hand, sustained transfer concerned only half of the learning outcomes from the ESAP course to the engineering courses. Interestingly, Hill et al.'s (2020) findings also showed that the learning outcome, whether general or specific, did not seem to have affected transfer.

In sum, the above-reviewed studies have provided insights into the transfer of learning outcomes in EGAP and ESAP contexts. However, the existing body of research that has investigated the transfer of learning outcomes to subject-specific courses still includes significant gaps, given the small number of studies that are available. More studies are needed, especially those that take into consideration the multiple dimensions of learning transfer (Barnett \& Ceci, 2002) and the conditions under which transfer occurs (Perkins \& Salomon, 1988). Shrestha's (2017) study targeted far transfer in an ESAP context; however, it was not based on a clear transfer taxonomy. In addition, while Hill et al.'s (2020) study was perhaps the unique study to have implemented Barnett and Ceci's (2002) transfer taxonomy in order to investigate the impact of a one-semester ESAP course on the transfer of learning outcomes to an engineering course, it focused on only two dimensions of this taxonomy and targeted only near transfer. Including more dimensions of Barnett and Ceci's (2002) transfer taxonomy in ESAP studies may give a clearer picture of learning transfer. The present study aimed to fill in these gaps by investigating the impact of a two-semester ESAP course on the transfer of learning outcomes to three subject-specific courses, TEFL, literature, and cultural studies. In other words, both near transfer and far transfer were targeted. Using four dimensions of Branett and Ceci's (2002) transfer taxonomy, the study sought to find out what type of transfer occurred most (near or far transfer), which learning outcomes transferred most and to where, and finally, whether there was a difference between the researcher's identified transfer and the students' identified transfer.

\section{Methodology \\ 3.1 Research context}

The study was conducted in a Tunisian university of humanities during the academic year 2015-2016. It involved three groups of third-year students majoring in English. However, only 40 students participated in the study because it was not possible to collect all the required data from all the students. Apart from the mandatory two-semester reading/writing course that they had to study, the students studied other core subjects, including TEFL, literature and cultural studies. These three content subjects were selected to be the focus of this study because they required the written examination prompt as the main form of evaluation at the end of instruction. Prior to the present study, the reading/writing course used to follow the EGAP model. However, since the main aim of any academic writing course is to equip students with the necessary skills that would enable them to write better in their content subjects (Leki \& Carson, 1997), it was deemed useful to try the ESAP model and to see whether it could offer students better learning opportunities than EGAP. The ESAP writing course was based on an adapted version of the adjunct model of Content-Based Instruction (CBI). The adjunct model links an EAP course to a concurrent content course and is generally 
co-taught by the subject teacher and the EAP teacher (see Snow \& Brinton, 1988). It can also be taught by a single teacher who possesses the subject knowledge and the language teaching expertise.

In the present study, the ESAP reading/writing course was linked to the TEFL course. It started in mid-September and ended in April. The researcher taught both subjects, following the belief that subject specialists should play a direct role in helping students develop their academic literacy (Wingate, 2016). The course was based on the reading and writing skills required in the TEFL course. For example, the TEFL reading materials served to teach skills and strategies such as skimming, scanning, paraphrasing, summarizing, synthesizing, and citing. Students were also trained to write the essay type required for the final TEFL exam, which was based on the discussion genre. Writing instruction drew largely on SFL genre pedagogies, namely the teachinglearning cycle for genre teaching (Rose \& Martin, 2012). Students were introduced to the discussion genre by highlighting its features in terms of the social context in which it is used and the social purpose it serves. Next, model essays were analyzed for their schematic structures and their linguistic features. Then teacher and students engaged in joint construction of the genre, and finally, students were encouraged to produce the genre independently. After all these stages, students were provided with a model discussion essay based on the TEFL content.

Although the two-semester ESAP course was in great part linked to the TEFL course, a unit of materials on analyzing fiction was included in the first-semester course. Students applied the discussion genre to two short stories. Applying the discussion genre to literature besides TEFL was done for two main reasons. First, examination prompts with the instructional verb discuss are also very common in literature and cultural studies in the English department. Second, students had the opportunity to see how such prompts can be answered in courses other than TEFL. This literature unit was enhanced by a short collaboration with a literature specialist. The researcher and the fiction lecturer jointly prepared a model essay on a topic related to a novel the students were studying in their fiction class at that time. Near the end of the first semester, this model essay was presented to all third-year students in a one-hour lecture that was co-taught by the literature lecturer and the researcher. During that session, the researcher's role consisted of highlighting the organizational features of the model essay, focusing on the moves of each main part of the essay from the introduction to the conclusion. Other aspects that were emphasized included writing critically, inserting quotations, and commenting on quotations, among others. The lecturer's role consisted of intervening whenever necessary to clarify content, comment on some literary techniques, and emphasize the organizational features of the model essay. Through this session, it was hoped that students could better make the link between what was taught in the writing class and what was needed in the fiction course.

In order to maximize the chances for learning transfer to occur, Salomon and Perkins' (1988) hugging and bridging strategies for teaching for transfer were carefully implemented (see Kassab, (2021) for a detailed description of how these techniques can be incorporated in writing instruction). The hugging strategy was meant to meet the conditions of low road transfer and thus of near transfer. Bridging was meant to meet the conditions of high road transfer and of far transfer. During the course, students were encouraged to think about how they could use the skills, the rules, and the principles that they learned in their other literature courses (fiction, drama, and poetry) and in their cultural studies courses (British history and American history). They were also encouraged to reflect on their overall learning cycle by writing reflective journal entries on a regular basis during the academic year.

\subsection{Near transfer versus far transfer}

The present study targeted both near and far transfer. The distinction between the two was made by using four elements of Barnett and Ceci's (2002) transfer taxonomy. James' (2014) application of this transfer taxonomy to EAP contexts also informed this study. Concerning the content of transfer, two dimensions were used. They included the learned skill and memory demands. As mentioned earlier, the learned skill refers to the nature of learning in terms of specificity/generality. Ten learning outcomes were targeted for transfer. They were classified in terms of specificity/generality as shown in Table 3.1. The definitions of the learning outcomes from 1 to 5 are the definitions used in Spack's (2007) textbook that was partly used during instruction.

Table 3.1: Learning outcomes and definitions

\section{Targeted learning outcomes}

1. Summarizing

Extracting the most important points needed for analysis

\section{Paraphrasing}

\section{Definitions}

Specific/

General

General

Clarifying an author's idea by

\section{Examples (Samples from students' written exams)}

Green et al. (2002) argue that to be able to conduct a good discussion, the activity must contain three stages which are pre-discussion, while discussion and post discussion... (From TEFL exam)

General Some of them [teachers] tend to rely too much 
restating its meaning using different vocabulary and syntax

\section{Synthesizing}

Combining two or more sources focusing on similarities and differences between readings

4. Quoting

Selecting pertinent quotations and integrating an author's words into the essay smoothly and appropriately

5. Citing ideas

Identifying the sources within the essay to give credit to another writer's work

Examples: contrast connectives, evidential verb hedges, code glosses, and modal hedges through discourse markers

7. Achieving unity

Each body paragraph develops one specific idea that is relevant to the assigned topic and related to the topic sentence.
8. Writing an introduction
An introduction that contains three moves:

- General statements

- Issue/thesis

- The scope of the essay on the textbook, restricting themselves to it and expecting their students to attend their classes, when students are able to do the same thing alone at home (Quinonez, 2014). (From ESAP writing exam)

General Quinonez (2014) asserts that it is the responsibility of the teacher to encourage the students to attend the lesson [...]. Moreover, St Clair (1999) claims that when students are forced to attend their lessons, there is a risk that they start thinking of quitting college [...]. (From the ESAP writing exam)

General The governess intimidates Flora into confessing that she sees the ghost of Miss Jessel, saying, "she's there you little unhappy thing" (James, ch. 20), when neither Flora nor Mrs Grose actually see her. (From fiction exam)

General According to Corbett (2014), attendance provides students with input that cannot be found in textbooks. (From the ESAP writing exam) Some of them [teachers] tend to rely too much on the textbook [...] when students are able to do the same thing alone at home (Quinonez, 2014). (From ESAP writing exam)

General Even though the 1960's were not as prosperous as the 1950's, people showed more courage to express their dissatisfaction. (From cultural studies exam)

Some of them tend to rely too much on the textbook. (From ESAP writing exam)

In other words, when making attendance obligatory, students may attend the lecture but for other reasons rather than understanding the course. (From ESAP writing exam)

General Some people believe that class attendance should be made voluntary. Quinomez (2014) argues that class attendance should not be an obligation [...]. In addition, Quinomez (2014) claims that most students who attend their lessons are either daydreaming or chatting [...]. Moreover, St Clair (1999) claims that when students are forced to attend their lessons, there is a risk that they quit college. [...] (From ESAP writing exam)

Specific The university is a whole new world for students, with new systems, more specialized subjects and strict administrative policies. For some students, the university means hard work and constant participation in class. [...]. That's why, teachers struggle with low attendance, which makes them question the importance of making it obligatory

[Move 1]. While some believe that class attendance is a personal decision, others consider it compulsory [Move 2]. This essay will first deal with class attendance as a student's choice. Then it will deal with the view that 
attendance should be obligatory. [Move 3] (From ESAP writing exam)

\section{Using topic} sentences
Each body paragraph must contain a topic sentence that states the first argument or idea to be discussed
Specific

According to some scholars, the governess emerges as the very embodiment of evil and mental disturbances. (From fiction exam)

The 1950's were depicted as a decade of affluence and prosperity. (From US history exam)

\section{Writing a conclusion with two moves}

\section{A conclusion that contains two}

moves:

- A restatement of the issue and main ideas

- A final opinion or recommendations
Specific

To conclude, the gothic novel still represents a controversial story. Some may believe that the governess' intentions are good and that she is trying to save the children from the dreadful ghosts [...]. Others believe that she has done more damage to them than good because of her imaginations of unreal ghosts. These ghosts are argued to be the reflection of her sexual repression ... [Move 1]. While this might be more plausible, readers are left to imagine the story the way they please, as long as it still causes mixed feelings. [Move 2]

(From fiction exam)

This classification helped distinguish between the learning outcomes that tend to transfer along the low road, leading to near transfer and those that tend to transfer along the high road, leading to far transfer (Perkins \& Salomon, 1988, James, 2014). The outcomes from 1 to 5 are related to content. The remaining ones are related to organization. Summarizing and paraphrasing are classified as general because they can be challenging for students and require a lot of training to master (Jordan, 1997). Students were supposed to have received some practice with these two skills in the two previous years. Synthesizing is more challenging for learners because it involves highly complex processes such as "reading, understanding, learning, relating, planning, writing, revising, editing, and orchestrating" (Campbell, 1990, p. 211). Expressing criticality through discourse markers is also a complex skill that takes time to develop (All \& Lancaster, 2014). Citing and quoting can also pose problems to undergraduate students. Students had been introduced to these four skills in the ESAP course for the first time. All the skills that are classified as general tend to transfer along the high road. Finally, the three last learning outcomes were classified as specific because they refer to knowledge of a specific procedure such as knowledge of the three-part structure (introduction, body, and conclusion) of an essay and knowledge of the number of moves in introductions, in body paragraphs, and in conclusions. These learning outcomes may transfer along the low road.

Concerning the memory demands dimension, the ESAP course and the TEFL course were classified as near because learning transfer was expected to occur as a result of hints. As explained earlier, the activities, skills, and exam writing genre that students practiced in the ESAP course were made similar to those needed in the TEFL course. Literature and cultural studies were classified as far because learning transfer was expected to occur spontaneously. That is, students were expected to make generalizations and to find similarities between the initial learning context (the ESAP course) and these transfer contexts. As for transfer distance, two dimensions were taken into consideration: the knowledge domain and the temporal context. Near transfer was expected in the ESAP course and TEFL because these two subjects were linked during instruction, and students were examined on the same writing genre. Far transfer was expected in literature and cultural studies because the exam writing genre may be different from the writing genre practiced in the ESAP course. The temporal context refers to the time that separates writing instruction and testing. The ESAP course and TEFL were classified as near because testing occurred almost immediately after instruction. Literature and cultural studies were classified as far because testing occurred three weeks after the end of writing instruction.

\subsection{Research design}

A longitudinal mixed methods design was adopted in order to reach a better understanding of learning transfer. James (2010a) notes that using qualitative methods to investigate learning transfer in complex real-world situations such as EAP contexts can bring to light many of the nuances of the transfer phenomenon that would not be possible to uncover through one-time only measures that have been predominant in transfer research. As noted earlier, failure to identify transfer in the cognitive tradition was due to the overreliance on the one-shot tests that were conducted under strictly controlled conditions and in complete isolation of the surrounding environment (Bransford \& Schwartz, 1999). In fact, incorporating qualitative methods in this 
research would take into account that learning is situated, in that it does not occur in isolation of the learning environment (Lave \& Wenger, 1991). In other words, the qualitative side can bring more clarity to the processes learners go through when attempting to learn and apply the practices that are valued by their academic community. In addition, as stated by Lobato (2012), understanding the reasoning processes that learners use between initial learning and transfer situations and understanding the role of the social context in this can be done through qualitative methods and not experimental ones. A longitudinal mixed-methods approach would also take into consideration the fact that transfer of learning is a long process. As stated by Haskell (2001) "significant transfer requires time to incubate; it tends not to occur instantaneously" (p. 46). In the same line, Salomon and Perkins (1989) assert that both low road and high road transfer require a certain degree of mastery of initial learning as well as sufficient time for practice. Concerning writing, Hyland (2016b) argues that "writing research [...] largely follows a 'relativist' orientation and favors more qualitative, natural, and 'thicker' data collection techniques" (p. 119). For Hyland (2016b), the data collection process should be best conducted in authentic circumstances. The present study was conducted under completely normal classroom conditions by the researcher who was responsible for both teaching the EAP writing course and collecting the data. In addition, the whole data collection process occurred in entirely authentic circumstances, in that it did not require any extra effort or extra time from students during the delivery of the course.

\subsection{Data collection}

Three types of data were collected: analysis of students' written texts, a student questionnaire, and semi-structured student interviews. The analysis of students' written texts served to answer the first research question: what transferred and to where from the researcher's point of view. They included students' written exams that were collected from four subjects and at two different points in time. Table 3.2 summarizes the number of writing samples collected for analysis.

Table 3.2: Number of writing samples used for analysis

\begin{tabular}{|c|c|c|c|c|c|}
\hline & ESAP & TEFL & Literature & Cultural studies & Total \\
\hline Semester 1 & 40 & 40 & 40 & 40 & \multirow{2}{*}{$N=320$} \\
\hline Semester 2 & 40 & 40 & 40 & 40 & \\
\hline
\end{tabular}

Students were informed of the purpose of the present study right from the beginning of the ESAP course. They were requested to allow copies of their mid-term writing and TEFL exams to be photocopied for research purposes. As for their literature and cultural studies exams, permission was sought to have access to these exams from the administration. In total, 320 mid-term written exams were collected for analysis from 40 students.

The questionnaire and the semi-structured interview served to answer the second research question: what transferred and to where from the students' point of view. The questionnaire was administered at the end of the academic year. It aimed to determine the extent to which the two-semester ESAP writing course helped students improve their academic writing skills over time and whether they tried to use the targeted skills when taking the second semester TEFL exam. The questionnaire was designed on a five-point Likert scale. It comprised three sections. Section 1 focused on the extent to which students thought that the ESAP writing course helped them improve their academic writing skills. Each closed-ended item consisted of a statement that represented a learning outcome. Section 2 of the questionnaire aimed to determine the extent to which students thought it was important for them to apply the skills mentioned in Section 1 when they took the second semester TEFL exam. This second section ended with an open-ended question that was related to the option "Not important". In case students chose this option, they were asked to explain why they thought it was not important for them to use the targeted skills when writing the TEFL exam. Section 3 of the questionnaire was brief and concerned the second semester literature and cultural studies exams that students had not taken, yet. It sought to get a general idea of the extent to which students would consider using the targeted skills when sitting for these exams which they would take approximately two weeks after the end of the second semester ESAP writing course. All the 40 participants completed the questionnaire when the researcher met with the students for the last time at the end of the academic year.

The semi-structured interview was conducted with twelve students at the end of the academic year. Four students were selected from each of the three groups that were taught by the researcher. Students were not interviewed individually but rather in groups of four. Group interviewing was considered the most suitable technique in this study for a number of reasons. Cohen et al. (2007) list some advantages of group interviews. First, group interviews can generate a wider variety of responses than individual interviews. Second, they are quicker than individual interviews and thus less time-consuming. Third, they may be more practical for teachers as they can be used with minimum disruption. Similarly, Hopkins (2008) "[finds] group interviews with three or four students the most productive" (p.110) because respondents can lead each other to more meaningful discussions. 
The researcher met with each group of interviewees just after the end of the last session of the second-semester course when all students received their writing and TEFL exams back. The interviewees received their exam papers at the end of the interviews and not during the feedback session with their classmates. This was done on purpose so that students' responses to the interview questions would not be influenced by the marks that they received nor by the teacher's written comments on their exam papers. Students were first asked to explain the extent to which the ESAP writing course helped them improve their academic writing skills. Other questions that students were invited to answer related to whether the ESAP writing course helped them improve their writing in the TEFL course and whether the writing skills they had learned could also be applied to literature and cultural studies. Following Dornyei (2007), all participants were given the same chances to answer the same questions without seeking to present these questions in the same order or wording. In addition, all the main questions were supplemented with a variety of probes (Dornyei, 2007). The three interviews took about 24 minutes each to complete. They were later transcribed.

\subsection{Data analysis}

The analysis of the writing samples was based on the technique used by James (2010a). As mentioned earlier, the ten targeted learning outcomes were classified into two broad categories related to content and organization. Identifying evidence of application of the learning outcomes in the writing samples was conducted following a number of criteria. For the writing, TEFL, and cultural studies exams, students were expected to use summarizing and paraphrasing when referring to their course materials. Students had to clearly specify each source they were referring to then summarize main ideas or arguments using paraphrasing. In the literature exams, students had to use summaries and paraphrases appropriately. For example, too much summary of the literary work in the literature exams was not considered as evidence of transfer. On the other hand, paraphrases that contained language problems but did not obscure meaning were accepted as evidence of transfer. Concerning synthesizing, students had to cite, combine, and compare at least two sources in each body paragraph. A synthesis that contained language problems but did not obscure meaning was considered as evidence of transfer. As for quoting, students had to select pertinent quotations and incorporate them smoothly and appropriately into their texts. Finally, citing refers to the correct use of the APA style for in-text citations for the writing, TEFL, and cultural studies exams and of the MLA style for in-text citations for literature.

The remaining learning outcomes mostly reflect the organizational features of the discussion essay genre that was targeted in the ESAP writing course. The identification of these learning outcomes would reflect the extent to which students could transfer the generic and linguistic features of the discussion genre from the ESAP course to the other content courses. As mentioned earlier, the exam topics of the writing and the TEFL exams were designed in a similar way because students were expected to apply the organizational and linguistic features of the discussion essay in both subjects. The exam prompts always contained the instructional verb discuss. As for literature and cultural studies, the exam prompts were designed in ways that looked different from the writing and TEFL exam prompts. The difference was in the use of the instructional verbs. For cultural studies, the exam prompts in both semester 1 and 2 included the double instructional verbs explain and comment. The first-semester poetry contained the instructional verb analyze and the second-semester fiction exam contained the instructional verb explain.

Although these prompts contained instructional verbs other than the instructional verb discuss, they seemed quite similar to the reading/writing and TEFL exam prompts. In other words, the organizational structures that they called for seemed quite similar to those of the discussion essay that students practiced extensively during reading/writing instruction. In addition, the analysis of the literature and cultural studies exam keys helped give some information - though in some cases too general - about the organizational structures of the exam prompts. The common requirement that was observed in all the exam keys was that students were required to write a well-organized essay with an introduction, body paragraphs, and a conclusion. The exam keys emphasized the importance of the thesis statement in the introduction. The exam keys of S1 cultural studies and S2 fiction stated clearly that the introduction must comprise three moves: introductory statements, thesis, and scope. On the other hand, while criticality was highly emphasized in the literature exam keys, it was less obvious in cultural studies since instructions for grading were mostly focused on content. In sum, there were enough indications that students could organize their answers around the discussion genre in their literature and cultural studies exams in case they were able to identify the similarities between this writing genre and the exam prompts in question. The criteria that were used to identify evidence of transfer of these organizational features are presented in Table 3.3.

Table 3.3; Criteria for evidence of transfer

\begin{tabular}{ll}
\hline Learning outcome & Criteria for evidence of transfer \\
\hline Writing an introduction & $\begin{array}{l}\text { The introduction must contain three moves: introductory statements, issue/thesis, } \\
\text { and the scope of the essay. } \\
\text { - An introduction that contained introductory statements, the issue/thesis, but no } \\
\text { scope was accepted as indicator of transfer. }\end{array}$ \\
\hline
\end{tabular}


Writing topic sentences

Achieving unity

Expressing criticality

discourse markers
Each body paragraph must contain a topic sentence that is clearly distinguishable from the supporting details.

Each body paragraph must develop one specific idea that was relevant to the assigned topic and must be related to the issue/thesis.

through - Using discourse markers to add criticality to the analysis, for example, contrast connectives, approximative hedges, evidential verb hedges, and reporting verbs.

- Discourse markers that were incorrectly or inappropriately used were not accepted as evidence of transfer.

- Overuse of discourse markers (e.g., every single sentence started with a discourse marker) was not accepted as evidence of transfer.

Writing a conclusion main ideas and the students' final opinion or recommendations

All students' writing samples ( $N$ 320) were analyzed for the application of the ten learning outcomes in order to reach a better understanding of the impact of the ESAP writing course on learning transfer. At first, a number of writing samples from each exam were coded many times and at different times by the researcher. They were further discussed with an experienced writing teacher to ensure that the learning outcomes could be easily identified. After that, the researcher coded all the writing samples. Evidence of application of the learning outcome was marked by "Yes", and no evidence of application was marked by "No". Once exams were coded for the application of the ten learning outcomes, percentages of the learning outcomes that students could transfer were drawn.

As for the questionnaire, students' responses were organized around three major themes: (1) the language skills that the participants perceived that they had developed in the ESAP writing course, (2) the language skills that the participants perceived that they had transferred to the TEFL course, and (3) the usefulness of these skills to the other courses, literature and cultural studies. The next step consisted of classifying the participants' responses into categories (Nunan, 1992) relating to the types of skills that the participants perceived that they had learned and transferred to other courses. Because the questionnaire was used among other tools to explore students' perceptions of the ESAP writing course and of learning transfer, it was deemed appropriate to use simple descriptive measures such as percentages (Hyland, 2003) to identify the general features of the participants' responses.

Concerning the analysis of the interview data, the techniques used drew on suggestions for the analysis of qualitative data (Corbin \& Strauss, 2007) as well as on the techniques used in research on learning transfer in EAP writing contexts (James, 2010a). In a first step, the interview transcripts were read a number of times from beginning to end in order to get a sense of them. The second step consisted of breaking down the transcripts into units of analysis that represented two major themes: (1) students' perceptions of the ESAP writing course and (2) students' perceptions of learning transfer. Once these two major themes were identified, the transcripts were read again in order to identify all the turns that could be classified under students' perceptions of the ESAP writing course. These turns were further classified into sub-categories, such as students' perceived learning of new skills and strategies and students' general attitudes towards their new learning experiences during the academic year. Finally, the transcripts were re-read to identify evidence of learning transfer. This stage consisted of examining the transcripts for the turns that made explicit mention of the learning outcomes that the participants thought they had applied in the reading/writing and TEFL exams or would apply in other courses.

\section{Results and Discussion}

The present study aimed to investigate the transfer of learning outcomes from an ESAP writing course to subject-specific courses. The first part of this section presents the results obtained from the analysis of students' writing samples that aimed to answer the first research question: what learning outcomes transferred and to where (researcher's identified transfer). The second part presents the results from the questionnaire and the semi-structured interviews that served to answer the second research question: students' perceived transfer.

\subsection{Analysis of writing assignments}

Table 4.1 presents the results from the analysis of the students' writing samples. The findings shed light on the type of learning outcomes that transferred in terms of specificity/generality of the learned skills and in terms of transfer distance (Barnett \& Ceci, 2002). In their investigation of the transfer of learning outcomes in an ESAP course, Khoo et al. (2020) considered only near transfer, and they found that the transfer of learning outcomes was not affected by the specificity/generality of the learned skill. This finding is in contrast with the findings of the present research. Table 4.1 showed that the frequency of transfer depended not only on transfer distance but also to a great extent on whether the learned skill is specific or general. 
Table 4.1: Percent transfer of learning outcomes

\begin{tabular}{lcccccccc}
\hline & S1 RW & S2 RW & S1 TEFL & S2 TEFL & S1 Lit. & S2 Lit. & S1 Cult. & S2 Cult. \\
\hline Sum. & $22.50 \%$ & $47.50 \%$ & $00.00 \%$ & $32.50 \%$ & $15.00 \%$ & $22.50 \%$ & $00.00 \%$ & $00.00 \%$ \\
\hline Paraph. & $20.00 \%$ & $25.00 \%$ & $02.50 \%$ & $35.00 \%$ & $15.00 \%$ & $22.50 \%$ & $00.00 \%$ & $00.00 \%$ \\
\hline Synth. & $07.50 \%$ & $30.00 \%$ & $00.00 \%$ & $15.00 \%$ & $00.00 \%$ & $00.00 \%$ & $00.00 \%$ & $00.00 \%$ \\
\hline Qt. & $10.00 \%$ & $07.50 \%$ & $00.00 \%$ & $00.00 \%$ & $15.00 \%$ & $07.50 \%$ & $00.00 \%$ & $00.00 \%$ \\
\hline Cit. & $17.50 \%$ & $47.50 \%$ & $02.50 \%$ & $62.50 \%$ & $00.00 \%$ & $00.00 \%$ & $00.00 \%$ & $00.00 \%$ \\
\hline Intr. & $70.00 \%$ & $87.50 \%$ & $52.50 \%$ & $57.50 \%$ & $22.50 \%$ & $82.50 \%$ & $15.00 \%$ & $55.00 \%$ \\
\hline T.S. & $80.00 \%$ & $90.00 \%$ & $75.00 \%$ & $77.50 \%$ & $80.00 \%$ & $85.00 \%$ & $27.50 \%$ & $82.50 \%$ \\
\hline Uty. & $22.50 \%$ & $32.50 \%$ & $02.50 \%$ & $15.00 \%$ & $10.00 \%$ & $12.00 \%$ & $05.00 \%$ & $12.50 \%$ \\
\hline Cohs. & $10.00 \%$ & $25.00 \%$ & $02.50 \%$ & $40.00 \%$ & $22.50 \%$ & $27.50 \%$ & $02.50 \%$ & $10.00 \%$ \\
\hline Concl. & $32.50 \%$ & $45.00 \%$ & $30.00 \%$ & $40.00 \%$ & $32.50 \%$ & $42.50 \%$ & $17.50 \%$ & $37.50 \%$ \\
\hline Summarizing & Paraph. = Paraphrasing Synth. = Synthesizing & Qt. = Quoting Cit. = Citing & Intr. = Introduction \\
\hline Topic sentences & S.D. = Supporting details & Uty. = Unity & Cohs. = Cohesion & Concl. = Conclusion
\end{tabular}

The first observation that can be made from Table 4.1 is that the transfer of learning outcomes occurred mostly in the near transfer contexts (ESAP course and TEFL). The second observation is that the learning outcomes that the students were able to transfer to the near transfer contexts concerned those that were classified as specified in the first place. These learning outcomes related to the surface structure of the discussion genre, including an introduction with three moves, body paragraphs with topic sentences and supporting details, and a conclusion with two moves. For example, in S2 ESAP, students' mastery of the three-part structure of the essay and the move structure of each essay part was obvious. A good majority (87.50\%) could write an introduction with the required three moves. As for the body paragraphs, an overwhelming majority (90\%) could write body paragraphs in which the topic sentences could be distinguished from the supporting details. Students' transfer of the threemove structure of the essay was also observed in the TEFL exams, though to a lesser degree than in the ESAP writing course. This transfer was also significant in the second semester with, for example, 57.50\% for the move structure of the introduction, $77.50 \%$ for topic sentences, and $40 \%$ for the two-move structure of the conclusion. These features were easily identifiable in a good majority of the students' ESAP and TEFL exams. These writing features appeared to have transferred easily because they tend to transfer along the low road (Perkins \& Salomon, 1988). Perkins and Salomon (1988) define low road transfer as "the automatic triggering of well-practiced routines in circumstances where there is a considerable perceptual similarity to the original learning context" (p. 25). In other words, low road transfer occurs spontaneously and automatically because it involves the transfer of skills to the contexts that share considerable similarities with the original context. This was largely the case in the present study. The fact that the ESAP writing course was linked to the TEFL course made the two courses almost identical in terms of activities, skills, strategies, and writing genres. The findings showed that writing an introduction with three moves, writing body paragraphs containing topic sentences and supporting details, and writing a conclusion seemed to have been almost an automatic process. However, as noted by Salomon and Perkins (1989), fifty hours of practice or even two years of practice may not be sufficient to reach near-automaticity. Thus, the fact that students in the present study were able to transfer these learning outcomes rather easily may have also been enhanced by the practice that they had done in their first year and second year writing courses. In sum, results showed that a good majority of students showed a clear understanding of the surface features of the examination essay and avoided writing answers in one block.

On the other hand, the findings indicated that the more demanding learning outcomes, summarizing, paraphrasing, synthesizing, citing, unity, and use of discourse markers did not transfer as easily as the other learning outcomes. In S1 ESAP this transfer was too constrained, with, for example, $22.50 \%$ for summarizing, $07.50 \%$ for synthesizing, and $22.50 \%$ for unity. On the other hand, these learning outcomes hardly transferred to the TEFL course. For example, students' writing performance in this exam was poor in terms of organization (unity). The results showed that in terms of unity, students tended to imitate too closely the structure of the TEFL model essay that had been used during instruction. In fact, while the first semester TEFL exam and the model essay shared some similarities, they slightly differed in terms of organization, namely unity. Results showed that an overwhelming majority of students attempted to follow the exact structure of the model TEFL essay used during instruction. The apparent negative impact of the use of modals in the present study lends support to Macbeth (2010) who found that the use of sample texts or models have their own limitations. She argues that "[modals] offer formal, generic representations of social practices that are far from generic or formally structured. They convey these practices not only as formal and structured, but stable, reliable, and vividly so" (p. 45). From a learning transfer perspective, the limited role model texts played in the present 
study is in line with the research findings that demonstrated that students generally cannot solve problems when these problems slightly differ from the examples given. Indeed, similar to Chi and Bassok's (1989) findings, the analysis of the students' writing samples in the present study showed that students appeared to have used the modal essay as "an algorithm" (Chi and Bassok', 1989, p. 260) that they had followed closely by focusing only on the obvious and superficial similarities between the model and the exam prompt.

Results from the analysis of the second semester ESAP and TEFL exams revealed a noticeable improvement in the students' ability to transfer the complex learning outcomes into their writing, although this transfer was still rather constrained. For example, in the ESAP course, transfer reached $25 \%$ for paraphrasing, 30\% for synthesizing, and $32 \%$ for unity. For TEFL, transfer reached $35 \%$ for paraphrasing, $15 \%$ for synthesizing, and $15 \%$ for unity. Interestingly, a rather significant transfer was observed at the level of the use of discourse markers (40\%) in S2 TEFL. Compared to semester 1, this improvement in the transfer of learning outcomes in semester 2 can be considered significant for two reasons. First, these results reaffirm the idea that transfer is not instantaneous but rather requires time to develop (Haskell, 2001). Second, the fact that these skills transferred in a rather constrained way can be related to the fact that these complex skills are not easy to master and pose a real challenge to ESL/EFL students (Jordan, 1997). From a transfer perspective, these skills tend to transfer along the high road which, as stated by Perkins and Salomon (1988), involves a great deal of complex reflective thinking and depends largely on the students' metacognitive abilities. Indeed, taking synthesizing as an example, results showed that the transfer of this skill was too constrained (30\% for S2 ESAP and $15 \%$ for S2 TEFL). This indicates that students cannot be expected to master in one year a skill that involves highly complex processes (Campbell, 1990). The same is true for the use of discourse markers to establish a critical stance. Transfer of this learning outcome was still constrained despite the noticeable improvement that was observed in S2 TEFL. This lends support to Aull and Lancaster's (2014) findings which demonstrated that stance construction among novice undergraduate students is a challenging, long process that can take years to develop.

Concerning the far transfer contexts, results showed that the transfer of learning outcomes also depended on the specificity/generality of the learned skills. Similar to the near transfer contexts, the learning outcomes that transferred most were those classified as specific, that is, the surface features of the essay. This was particularly noticeable in the second semester exams. For example, in S2 literature, a good majority of students (82.5\%) could write a three-part introduction in which the issue was clearly stated and body paragraphs in which the topic sentences and the supporting details (85\%) were clearly distinguishable. As for the conclusion, a rather acceptable number of students (42.50\%) managed to write a conclusion that included the two required moves. For cultural studies, the transfer of the learning outcomes also occurred at the level of the move structure of the essay. It was rather acceptable at the level of the introduction (55\%) and noticeably significant at the level of topic sentences (82\%). As regards the conclusion, transfer did not exceed the $37.5 \%$. In other words, what students could transfer to the literature and cultural studies courses were the features that tend to transfer along the low road (Perkins \& Salomon, 1988). The ESAP writing course may have played a role in this since the relevance of these features to any essay writing in any subject were highly emphasized during instruction. Moreover, results showed that these surface features transferred somehow easily to both the near and far transfer contexts.

On the other hand, results showed that the transfer of the skills that were classified as general was limited and sometimes nonexistent. For example, there was rather limited transfer of summarizing (22.50\%) and paraphrasing (22.50) in S2 literature. There was totally no transfer of these two skills to cultural studies. In the latter subject, students seemed to rely entirely on their lecture notes through memorization. Synthesizing, quoting, and citing transferred neither to literature nor to cultural studies. One possible explanation for this can be related to the fact that such skills were not explicitly emphasized by the literature and cultural studies lecturers. Nonetheless, the findings showed that the learning outcomes that relate to organization (unity and use of discourse markers) transferred rather noticeably to S2 literature and S2 cultural studies compared to the learning outcomes that relate to content. These results also indicated that learning outcomes that tend to transfer along the high road can be much more difficult to transfer to the far transfer contexts than to the near transfer contexts. Thus, the learning outcomes that mostly transferred to the far transfer contexts were those related to organization, but they did not transfer equally, which was also the case in the near transfer contexts. These observations support James' (2010a) findings which demonstrated that the transfer of learning outcomes can vary among categories (e.g., content, organization, and language use) and can vary within categories themselves (e.g., essay three-part structure, topic sentences, unity, cohesion).

Furthermore, the fact that transfer occurred mostly at the level of organization in S2 literature can indicate that some students had tried to find some correspondences or similarities between the literature exam prompt and the writing tasks that they did during the writing course. This process is referred to as analogical transfer which involves finding similarities between two concepts or two situations (Gick \& Holyoak, 1983). Indeed, using analogies was one of the bridging techniques (Fogarty et al., 1992) that were used during writing instruction to promote far transfer. Students were constantly encouraged to find similarities between the writing they did in the writing course and the writing they needed to do in other courses. In fact, the S2 literature 
exam prompt shared some similarities with the writing tasks that students did during instruction. First, students practiced writing two discussion essays about fiction, and the literature exam prompt was also about fiction. Second, the wording of the fiction topics practiced during writing instruction was similar to that of the literature exam prompt. The only difference was in the use of the instructional verb explain instead of discuss. While Perkins and Salomon's (1988) bridging techniques seemed to have played a positive role in $\mathrm{S} 2$ literature exam, they did not have the same apparent effect on students' performances in the cultural studies exams. Indeed, although most students wrote essays with a three-part structure, they failed to approach the writing tasks from a critical perspective. The cultural exam prompt in S2 could have been developed following the discussion genre practiced in the writing course. However, the majority of students failed to see any correspondences or similarities between the exam prompts and the writing tasks they did in the writing course. This supports the view that spontaneously noticing similarities between problems and drawing analogous solutions is not an easy matter (Gick \& Holyoak, 1983). In the same vein, Haskell (2001) notes that students often fail to transfer their learning to new situations when similar problems are worded in a slightly different way. This was the case in the present study. The cultural exam prompts were worded in a way that looked different from the writing tasks the students did in the writing course. This might also explain why transfer did not occur at the level of unity, cohesion, and criticality in cultural studies. These findings also lend support to James's $(2008,2009)$ findings which showed that task similarity/difference can influence transfer.

\subsection{Students' perceived transfer}

This section aims to answer research question 2, that is what transferred from the students' perspectives. Table 4.2 presents the transfer of learning outcomes across the ESAP course. As can be seen, a big majority of the participants reported positive transfer. In addition, students' perceived transfer concerned the learning outcomes related to both content and organization. For example, of the 40 participants, a great majority reported using the three-part structure of the essay (Item 1 of the questionnaire), with $30 \%$ agreeing and $62 \%$ strongly agreeing. No participant disagreed or strongly disagreed. A good majority of the respondents reported having learned to structure their essays according to the discussion genre, with $52 \%$ agreeing and $37.5 \%$ strongly agreeing. The majority of the respondents indicated learning the move structure of the introduction in the discussion genre (Items 3 and 4) and the move structure of the body paragraphs (Item 5). As for the conclusion (Item 6), although a good number of the respondents ( $25 \%$ being neutral and $5 \%$ disagreeing) did not really feel that they had mastered the move structure of the conclusion, more than half of the respondents reported learning the two-move structure of the conclusion. Writing critically by using linguistic markers of stance was reported by a great majority of the respondents (Item 9). No participant reported having not learned how to express criticality through discourse markers of stance. Only $10 \%$ of the participants were not sure with this skill, while 52\% agreed that they had learned this skill and $37.5 \%$ strongly agreed.

Table 4.2: Students' perceived transfer of learning outcomes across the ESAP course

\begin{tabular}{|c|c|c|c|c|c|}
\hline When writing the ESAP writing exam, I tried to... & S.D & $\mathrm{D}$ & $\mathrm{N}$ & A & S.A \\
\hline $\begin{array}{l}\text { 1. write an essay with an introduction, body paragraphs, and a } \\
\text { conclusion. }\end{array}$ & 0 & 0 & $7.5 \%$ & $30 \%$ & $62.5 \%$ \\
\hline structure my essay following the discussion genre learned in class. & 0 & 0 & $5 \%$ & $52.5 \%$ & $37.5 \%$ \\
\hline $\begin{array}{l}\text { 3. write an introduction with a thesis statement that aims to answer the } \\
\text { question. }\end{array}$ & 0 & 0 & $15 \%$ & $35 \%$ & $50 \%$ \\
\hline 4. indicate the scope of the essay at the end of my introduction. & 0 & 0 & $15 \%$ & $40 \%$ & $45 \%$ \\
\hline 5. start body paragraphs with topic sentences that support my thesis. & 0 & $2.5 \%$ & $12.5 \%$ & $40 \%$ & $45 \%$ \\
\hline $\begin{array}{l}\text { 6. write a conclusion that restates the thesis and main ideas and ends } \\
\text { with recommendations or my opinion on the issue. }\end{array}$ & 0 & $5 \%$ & $25 \%$ & $42.5 \%$ & $27.5 \%$ \\
\hline use supporting evidence from the source texts. & 0 & $2.5 \%$ & $25 \%$ & $32.5 \%$ & $40 \%$ \\
\hline 8. use in-text citations. & 0 & $7.5 \%$ & $27.5 \%$ & $17.5 \%$ & $47.5 \%$ \\
\hline 9. use discourse markers of stance. & 0 & 0 & $10 \%$ & $52.5 \%$ & $37.5 \%$ \\
\hline 10. summarize the authors' main arguments. & $2.5 \%$ & $7.5 \%$ & $20 \%$ & $45 \%$ & $25 \%$ \\
\hline 11. paraphrase authors' ideas. & $0 \%$ & $2.5 \%$ & $12.5 \%$ & $45 \%$ & $40 \%$ \\
\hline 12. synthesize information from the source texts. & $0 \%$ & $5 \%$ & $32.5 \%$ & $37.5 \%$ & $25 \%$ \\
\hline
\end{tabular}

$S . D=$ Strongly disagree $\quad D=$ Disagree $\quad N=$ Neutral $\quad A=$ Agree $\quad S . A=$ Strongly agree

The results from the questionnaire also revealed a positive transfer of the learning outcomes related to content. Only $2.5 \%$ reported not learning how to use supporting evidence from source texts and $25 \%$ appeared to be unsure. In fact, a good majority of the participants reported learning how to use source texts for supporting evidence, with $32.5 \%$ agreeing and $40 \%$ strongly agreeing (Item 7 of the questionnaire). Concerning the use of in-text citations (Item 8), only $7.5 \%$ of respondents reported not using in-text citations. In addition, more than $60 \%$ of the participants reported using summarizing, with $45 \%$ agreeing and $25 \%$ strongly agreeing. Moreover, a great majority of the participants (about $80 \%$ ) reported using paraphrasing. 
Finally, although some $32 \%$ of the respondents seemed to be unsure about synthesizing, about $60 \%$ expressed confidence in using this skill. The same positive transfer of learning outcomes was reported for the TEFL course (Table 4.3). When asked to indicate how important it was for them to use the previously learned skills in the TEFL exams, the majority of students responded either "important" or "very important". For example, all of them mentioned that it was very important or important to write a three-part essay with an introduction, body paragraphs, and a conclusion (Item 1 of the questionnaire). A good majority (45\% important and 35\% very important) indicated that they had structured their essays according to the discussion genre (Item 2). In addition, a good majority reported using a thesis in the introduction, with $60 \%$ who indicated very important and $35 \%$ important. In terms of the surface structure of the essay, the majority of the respondents reported using the move structures of the introduction (introductory statements, thesis and scope), the body paragraphs, (topic sentences and supporting details), and the conclusion (restatement of the thesis and ending with general recommendations).

Table 4.3: Students' perceived transfer of learning outcomes from the ESAP course to the TEFL course

\begin{tabular}{|c|c|c|c|c|c|}
\hline When writing the TEFL exam, I tried to... & N.imp & S.imp & M.imp & Imp & V.imp \\
\hline $\begin{array}{l}\text { 1. write an essay with an introduction, body paragraphs, and a } \\
\text { conclusion. }\end{array}$ & $0 \%$ & $0 \%$ & $0 \%$ & $27.5 \%$ & $72.5 \%$ \\
\hline 2. structure my essay following the discussion genre. & $0 \%$ & $0 \%$ & $15 \%$ & $45 \%$ & $35 \%$ \\
\hline $\begin{array}{l}\text { 3. write an introduction with a thesis statement that aims to answer the } \\
\text { question. }\end{array}$ & $0 \%$ & $0 \%$ & $2.5 \%$ & $35 \%$ & $60 \%$ \\
\hline 4. indicate the scope of the essay at the end of my introduction. & $0 \%$ & $2.5 \%$ & $17.5 \%$ & $37.5 \%$ & $40 \%$ \\
\hline start body paragraphs with topic sentences that support my thesis. & $0 \%$ & $0 \%$ & $10 \%$ & $42.5 \%$ & $45 \%$ \\
\hline $\begin{array}{l}\text { 6. write a conclusion that restates the thesis and main ideas and ends } \\
\text { with recommendations or my opinion on the issue. }\end{array}$ & $0 \%$ & $5 \%$ & $15 \%$ & $55 \%$ & $22.5 \%$ \\
\hline use supporting evidence from source texts. & $0 \%$ & $2.5 \%$ & $20 \%$ & $45 \%$ & $30 \%$ \\
\hline use in-text citations. & $0 \%$ & $7.5 \%$ & $5 \%$ & $45 \%$ & $40 \%$ \\
\hline 9. use discourse markers of stance. & $0 \%$ & $2.5 \%$ & $12.5 \%$ & $42.5 \%$ & $40 \%$ \\
\hline 10. summarize main ideas and arguments stated in the source texts. & $0 \%$ & $2.5 \%$ & $20 \%$ & 47.5 & $27.5 \%$ \\
\hline 11. paraphrase authors' ideas. & $0 \%$ & $0 \%$ & $5 \%$ & $55 \%$ & $37.5 \%$ \\
\hline 12. synthesize information from source texts and course materials. & $0 \%$ & $5 \%$ & $30 \%$ & $37.5 \%$ & $27.5 \%$ \\
\hline
\end{tabular}
important

The participants' perceptions of the transfer of the more complex skills to the TEFL course were also very positive. Apart from a small minority who considered using in-text citations as slightly important or moderately important (12.5\%), the respondents indicated that it was very important or important for them to cite their sources in the TEFL exams. Criticality also appeared to be a very important aspect that the students were careful about since the overwhelming majority indicated that they tried to make their writing critical by using linguistic markers of stance. Furthermore, summarizing and paraphrasing were given very high importance, with a big majority of the respondents indicating that they had tried to use these skills in the TEFL exams. Finally, compared to the other skills, synthesizing was the skill that the participants appeared to have found the most challenging. A noticeable percentage of the respondents (about 35\%) indicated that they had considered synthesizing as moderately important to apply in the TEFL exams. Nonetheless, a good percentage (about 65\%) mentioned that they had considered it important $(37.5 \%)$ and very important (27.5\%) to synthesize information from the TEFL source materials. Students' perceived transfer of the learning outcomes was also observed in the far transfer contexts. Students' responses to Section 3 of the questionnaire concerned basically the participants' future intentions to use the skills they had learned in the reading/writing course. Moreover, the application of this new learning would also depend on the type of examination prompts that the students would have in the literature and cultural studies exams. Of the 40 participants who responded to this section of the questionnaire (Table 4.4), no one indicated that it would not be important or it would be slightly important to use the twelve learning outcomes listed in the previous sections of the questionnaire. In addition, only a small minority (about 6\%) indicated that it would be moderately important to use these skills.

Table 4.4: Students' perceived transfer of the twelve learning outcomes to literature and cultural studies

$\begin{array}{ccccc}\text { Not important } & \text { Slightly imp. } & \text { Moderately imp. } & \text { Important } & \text { Very important } \\ 0 & 0 & 5.71 \% & 48.57 \% & 45.71 \%\end{array}$

Results from the analysis of the interview transcripts showed that the learning outcomes that transferred most were also those related to organization and particularly to the surface features of essay writing. The learning outcomes that were mentioned by 
all the interviewees were the three-part structure of the essay, the two-move structure of the introduction, and the two-move structure of the conclusion as illustrated in the following interview excerpt.

Personally, I have problems with the introduction. I always keep a space and then move to the body paragraphs and then conclusion. But this year I learned that it is very important to start with an introduction which includes the general statements, thesis and the scope, then to move to the body paragraphs starting with a topic sentence in each paragraph which depends on our thesis and will end up with the conclusion that should include restatements and our recommendation. (Participant 1 from group interview 1)

Interestingly, some of the interviewees reported having learned the surface structure of the different parts of the essay for the first time in the ESAP course, although these features were also part of their first-year and second-year writing courses. For example, one participant from group interview 2 said:

The reading/writing course was so different from the years before. I remember in first year I had no idea what organization is, what to write in the introduction or in the other parts. I remember in the exam I got 5 and I was so shocked. That was so different what we dealt with in class. I had no idea what to write. So now I realize why I got that 5. Concerning organization, I think it's more clear for me what to write such as topic sentences and thesis statement. (Participant 1 from Group interview 2)

Another participant from group interview 3 also stated that it was the first time she had learned that the introduction should comprise introductory statements, a thesis statement, and a scope. She also did not know that the topic sentences should be related to the thesis statement:

Before I didn't know that in the introduction there should be three parts: the general statements, the thesis statement and the scope. It's the first time I heard about that. Also, I didn't know that each paragraph should start with a topic sentence that is directly related to the thesis. Before I used to start each paragraph the way I want. (Participant $1 \mathrm{from}$ group interview 3)

On the one hand, these students' responses indicate that the transfer of learning outcomes, being specific or general, is a long process. On the other hand, the students' negative attitudes towards their previous writing courses reflect what James (2010b) calls a negative transfer climate. In his study, James' (2010b) case study subjects mostly referred to their EAP writing courses in a negative way. They also reported seeing no relevance of these courses to their subject-specific courses. As can be inferred from the results obtained from the students' writing samples, the questionnaire, and the interviews, the ESAP writing course in the present study seemed to have offered a more positive transfer climate than the students' previous writing courses which were still based on the EGAP model. The analysis of the interview transcripts also yielded the same positive results in relation to the participants' perceived transfer of the surface features of the essay to the far transfer contexts. It is worth reminding that at the time of conducting the interviews, the participants had not taken yet the final literature and cultural studies exams of the second semester. Thus, when asked whether they would try to use the skills that they had learned in the ESAP writing course in literature and cultural studies, all the interviewees affirmed that they would. All of them reported being able to see a strong link between the skills learned in the writing course and the skills needed in literature and cultural studies. However, the learning outcomes that they explicitly and most frequently mentioned were related to organization and particularly to those classified as specific, that is, the surface features of the essay as illustrated by the following participant from group interview 1.

This combination between the TEFL course and the reading/writing course made me realize that literature and civilization need also an essay with similar sections to use, introduction body paragraphs and a conclusion. What's different is the content. So, we have to bear in mind that writing an introduction is not different from writing an introduction in reading/writing, TEFL, civilization and even literature. They have to encompass general statements, thesis, a scope, body paragraphs and a conclusion. (Participant 2 from group interview 1)

I see that what we have learned is very beneficial when writing in civilization and literature, especially in terms of organization, and for me I used to write the introduction without a thesis statement and without a scope. But now, I follow all these steps. (Participant 2 from group interview 2)

These positive results generally support the results obtained from the analysis of the students' writing samples. That is, in terms of specificity/generality, the learning outcomes classified as specific tended to transfer more easily to both the near transfer contexts (ESAP and TEFL) and to the far transfer contexts (literature and cultural studies). All the interviewees mentioned that the ESAP writing course helped them develop their academic writing skills in terms of content and organization. Summarizing,

Page | 55 
paraphrasing, and synthesizing were frequently mentioned as the skills that students had learned as illustrated in the following excerpts.

[I learned] many things: the language, how to think, how to synthesize, and how not to rely on memorization. I feel relaxed when I don't memorize things especially when I use synthesizing, summarizing and paraphrasing. I can restate what others say with my own words. Even though I don't start very well, but I try at least. (Participant 3 from group interview 1)

Actually, I didn't know what is meant by synthesizing. This is the first year I discover synthesizing. At the beginning, I felt it's so hard to adopt this technique but then you started explaining for us ... In the first semester I didn't understand it well to be honest but this semester I tried very hard and I tried to do it. (Participant 3 from group interview 2)

These students were quite aware that these skills are not easy to master. In fact, all the interviewees found these skills very difficult to use in their writing. Thus, learning about a new skill such as synthesizing is one thing, but mastering it is another matter. The other learning outcome that was frequently mentioned in the interviews was the use of discourse markers to express criticality. First, all interviewees mentioned that they had learned how to make their writing critical. For example, one participant stated that the course made her realize that a basic feature of academic writing is criticality:

Compared to last year I see an improvement. Last year I didn't recognize that academic writing should be critical. I didn't know the words that I should use to express criticality. (Participant 4 from group interview 2)

Some interviewees made explicit mention of some of the discourse markers of stance they had seen in the ESAP course. For example, one participant mentioned that she had learned that model hedges such as can and could are used to express criticality.

This year, I learned that criticality should be in the whole essay through the use of hedging like modals can and could. So, I think it is very important to be critical in your essay. (Participant 4 from group interview 1)

Although very few interviewees explicitly mentioned the discourse markers they had tried to use in their writing, they all mentioned that they had learned that they can make their writing critical by using specific language features. One participant mentioned that she learned that criticality is an essential feature that should be applied in all subjects.

The major common feature of all the subjects is criticality because in all the subjects we are required to keep a distance from what we are writing. Even in cultural studies, we're supposed to state some facts, but this doesn't mean that we don't have to be critical. Also in literature, we also tend to evaluate the topic from different perspectives. So, criticality is the major characteristic between all the subjects. (Participant 1 from group interview 3)

In sum, results from the students' interviews and the questionnaire responses showed that the transfer of the learning outcomes that were classified as general tended to transfer quite frequently, which was in contrast with the results obtained from the analysis of the students' writing samples. This is in line with Lobato's $(2003,2012)$ view that evidence for positive transfer can be reached when seen from a perspective that is different from the traditional view of transfer, that is, the direct application of previous learning to new situations. In other words, learning transfer can be much more significant when seen from students' perceptions. Moreover, Lobato (2012) asserts that what transfers from learners' perspectives can lead to a better understanding of the processes that learners use between initial learning and transfer situations. This was largely the case in the present study. Results from the students' interviews and the questionnaire responses provided valuable insights into how students' perceptions of their learning and of learning transfer developed over time. For example, students' perceived transfer of the more complex learning outcomes did not necessarily mean that they believed that they had mastered them. Instead, they seemed to have developed a great awareness of the importance of these skills for the development of their academic writing. As illustrated in the interview excerpts, all the interviewees clearly reported that, after one year of academic writing instruction, they still found the learning outcomes synthesizing and the use of discourse markers of stance very challenging. They surely still needed much more time and more opportunities to practice these skills not only in their EAP writing courses but also in their subject-specific courses. This supports the view that learning transfer should not only be considered as essentially the application of previous learning to new situations but also as an adaptive process (Bransford \& Schwartz, 1999; Lobato, 2003, 2012; DePalma \& Ringer, 2011). In other words, learning transfer should be seen as a dynamic process rather than as a static one. 


\section{Conclusion}

The present study aimed to investigate the transfer of learning outcomes from an ESAP writing course to subject-specific courses. Ten learning outcomes related to content and organization were targeted for transfer. Elements from Barnett and Ceci's (2002) transfer taxonomy were used. They helped classify the targeted learning outcomes in terms of specificity/generality and helped distinguish between near transfer and far transfer contexts. Results showed that the transfer of learning outcomes to both the near and far transfer contexts was clearly affected by the specificity/generality of the learned skills. Results from the analysis of the students' writing samples (researcher's identified transfer) indicated that the learning outcomes that were classified as specific transferred most frequently. These learning outcomes are related to organization and almost exclusively to the surface features of essay writing. They transferred rather easily to both the near and far transfer contexts. These results corresponded with the results obtained from the students' questionnaire and semi-structured interviews (students' identified transfer). On the other hand, the findings revealed that the learning outcomes that were classified as general transferred differently. Results from the writing samples showed that learning outcomes such as summarizing, paraphrasing, synthesizing, and using discourse markers of stance transferred in a very constrained manner to the near transfer contexts, and they hardly transferred to the far transfer contexts. These findings were in contrast with the findings obtained from the students' questionnaire and the interviews. Students' perceived transfer of the complex learning outcomes to both the near and far transfer contexts was generally positive. Finally, the findings demonstrated that one year of ESAP writing instruction was insufficient to help students transfer complex skills such as synthesizing and use of discourse markers of stance to their writing in other courses.

The findings of the present study have important implications for EAP writing instruction. First, they demonstrated that an ESAP writing course that incorporates teaching for transfer principles (Perkins \& Salomon, 1988) seems to offer students better chances to learn the required skills in a more authentic context than in an EGAP context. Second, learning outcomes, being specific or general, take considerable time to transfer. Students need ample opportunity to practice the skills not only in their writing courses but also in other contexts such as their content courses where they need these skills. This means that subjectspecific lecturers can play an important role in promoting transfer of learning by familiarizing themselves with the EAP writing content and making their expectations clear to both their students and the EAP writing instructors. Finally, the present study had some limitations that should be addressed in future research. The identification of the learning outcomes in students' writing samples in the present study included only one type of writing, which was the timed examination prompt. This type of essay writing, which is usually done in no more than two hours in the context of the present research, may be insufficient to give a clear idea about the transfer of learning outcomes from the initial learning contexts to the transfer contexts. It would be useful to examine other types of writing, such as the home assignments which require writing from sources. This type of writing can lead to a better understanding of the transfer of the more complex skills such as summarizing, paraphrasing, synthesizing, and the use of discourse markers of stance. Finally, it would be useful to investigate the role that the transfer climate can play in encouraging or impeding the transfer of certain learning outcomes.

Funding: This research received no external funding.

Conflicts of Interest: The author declares no conflict of interest.

\section{References}

[1] Aull, L.L. \& Lancaster, Z (2014). Linguistic markers of stance in early and advanced academic writing: a corpus-based comparison. Written Communication, 31 (2), 151-183. https://doi: 10.1177/0741088314527055

[2] Barnett, S. M., \& Ceci, S. J. (2002). When and where do we apply what we learn? A taxonomy for far transfer. Psychological Bulletin, 128, 612637.

[3] Bloor, M., \& Bloor, T. (1986). Languages for specific purposes: Practice and theory. CLCS Occasional Papers, 19. Trinity College, Centre for Language and Communication Studies.

[4] Bransford, J. D., \& Schwartz, D. (1999). Rethinking transfer: A simple proposal with multiple implications. Review of Research in Education, 24, 61-100. https://doi.org/10.3102/0091732X024001061

[5] Campbell, C. (1990). Writing with others' words: using background reading text in academic compositions. In B. Kroll (Ed.), Second Language Writing. Cambridge University Press.

[6] Chi, M. T. H. \& Bassok, M. (1989). Learning from examples via self-explanations. In L. Resnick (Ed.), Knowing, learning, and instruction: Essays in honor of Robert Glaser, pp. 251-282. Lawrence Erlbaum.

[7] Cohen, L.; Manion, L. \& Morrison, K. (2007). Research Methods in Education. Routledge.

[8] Corbin, J. \& Strauss, A. (2008). Basics of qualitative research: Techniques and procedures for developing grounded theory (3 ${ }^{\text {rd }}$ ed.). Sage.

[9] DePalma, M.-J., \& Ringer, J.M. (2011). Toward a theory of adaptive transfer: Expanding disciplinary discussions of 'transfer' in secondlanguage writing and composition studies. Journal of Second Language Writing, 20 (2), 134-147. https://doi.org/10.1016/j.jslw.2011.02.003

[10] Detterman, D. K. (1993). The case for the prosecution: transfer as an epiphenomenon. In D. K. Detterman, \& R. J. Sternberg (Eds.), Transfer on trial: Intelligence cognition, and instruction, pp. 1-24. Ablex Publishing Corporation.

[11] Dornyei, Z. (2007). Research methods in applied linguistics. Oxford University Press. 
[12] Duff, P.A. (2010). Language socialization into academic discourse communities. Annual Review of Applied Linguistics, $30,169-192$. doi:10.1017/S0267190510000048.

[13] Flowerdew, J. and Peacock, M. (2001). Issues in EAP: A preliminary perspective. In J. Flowerdew and M. Peacock (Eds.), Research perspectives on English for academic purposes. pp. 8-24. Cambridge University Press.

[14] Fogarty, R., Perkins, D., \& Barell, J. (1992). How to teach for transfer. Skylight Publishing.

[15] Gick, M. L., \& Holyoak, K. J. (1983). Schema induction and analogical transfer. Cognitive Psychology, 15, 1-38. https://doi:10.1016/00100285(83)90002-6

[16] Greeno, J.G. (1997). On claims that answer the wrong questions. Educational researcher, 26, pp. 5-17.

[17] Haskell, R. E. (2001). Transfer of learning: Cognition, instruction, and reasoning. Academic Press.

[18] Hill, C., Khoo, S., \& Hsieh, Y. (2020). An investigation into the learning transfer of English for Specific Academic Purposes (ESAP) writing skills of students in Singapore. Journal of English for Academic Purposes 48, https://doi.org/10.1016/j.jeap.2020.100908

[19] Hopkins, D. (2008). A teacher's guide to classroom research (4 ${ }^{\text {th }}$ ed.). Open University Press.

[20] Hyland, K. (2016a). General and specific EAP. In K. Hyland \& P. Shaw (Eds.), Routledge Handbook of English for Academic purposes, pp 17-29. Routledge.

[21] Hyland, K. (2016b). Methods and methodologies in second language writing Research. System, 59, 116-125. doi.org/10.1016/j.system.2016.05.002

[22] Hyland, K. (2006). English for academic purposes: An Advanced Resource Book. Routledge.

[23] Hyland, K. (2002). Specificity revisited: How far should we go now? English for Specific Purposes, 21, 385-395. https://doi.org/10.1016/S08894906(01)00028-X

[24] James, M.A (2014). Learning transfer in English-for-academic-purposes contexts: A systematic review of research. Journal of English for Academic Purposes 14, 1-13. https://doi.org/10.1016/j.jeap.2013.10.007

[25] James, M. A. (2010a). An investigation of learning transfer in English-for-general-academic- purposes writing instruction. Journal of Second Language Writing, 19, 183-206. https://doi:10.1016/j.jslw.2010.09.003

[26] James, M. A. (2010b). Transfer climate and EAP education: Students' perceptions of challenges to learning transfer. English for Specific Purposes, 29, 133-147. https://doi:10.1016/j.esp.2009.09.002

[27] James, M. A. (2009). "Far" transfer of learning outcomes from an ESL writing course: Can the gap be bridged? Journal of Second Language Writing, 18, 2, 69-84. https://doi:10.1016/j.jslw.2009.01.001

[28] James, M. A. (2008). The influence of perceptions of task similarity/difference on learning transfer in second language writing. Written Communication, 25, 76-103. https://doi: 10.1177/0741088307309547

[29] Johns, A. M. (1993). Reading and writing tasks in English for academic purposes classes: Products, processes, and resources. In J. G. Carson \& I. Leki (Eds.), Reading in the composition classroom, pp. 274-289. Heinle and Heinle.

[30] Jordan, R. (1997). English for Academic Purposes. Cambridge: Cambridge University Press.

[31] Kassab, K. (2021) An Investigation of Transfer of Learning in an English-for-Specific-Academic Writing Course: Teaching for Transfer. International Journal of Linguistics, Literature and Translation, 4 (2), 172-184. https://al-kindipublisher.com/index.php/ijllt/article/view/1363

[32] Larsen-Freeman, D. (2013). Transfer of Learning Transformed. Language Learning. 63: Suppl. 1, pp. 107-129. https://doi:10.1111/j.14679922.2012.00740

[33] Lave, J. \& Wenger, E. (1991). Situated learning: Legitimate peripheral participation. Cambridge University Press.

[34] Leki, I., \& Carson, J. G. (1997). Completely different worlds: EAP and the writing experiences of ESL students in university courses. TESOL Quarterly, 31, 39-69. https://doi.org/10.2307/3587974

[35] Lobato, J. (2012). The actor-oriented transfer perspective and its contributions to educational research and practice. Educational Psychologist, 47 (3), 232-247. https://doi: 10.1080/00461520.2012.693353

[36] Lobato, J. (2003). How design experiments can inform a rethinking of transfer and vice versa. Educational Researcher, 32, 1, 17-20. https://doi.org/10.3102/0013189X032001017

[37] Macaulay, C., \& Cree, V. E. (1999). Transfer of learning: Concept and process. Social Work Education, 18, (2), 183-194. https://doi:10.1080/02615479911220181

[38] Macbeth, K.P. (2010). Deliberate false provisions: The use and usefulness of models in learning academic writing. Journal of Second Language Writing 19, 33-48. https://doi:10.1016/j.jslw.2009.08.002

[39] Nunan, D. (1992). Research methods in language learning. New York: Cambridge University Press.

[40] Perkins, D. N., \& Salomon, G. (1992). Transfer of learning. Contribution to The International Encyclopedia of Education, Second Edition. Pergamon. Retrieved from http://jaymctighe.com/wordpress/wp-content/uploads/2011/04/Transfer-of-Learning-Perkins-and-Salomon.pdf

[41] Perkins, D. N., \& Salomon, G. (1988). Teaching for transfer. Educational Leadership, 46, 1, 22-32. Retrieved from http://www.ascd.org/ASCD/pdf/journals/ed_lead/el_198809_perkins.pdf.

[42] Rose, D. \& Martin, J.R. (2012). Learning to write, reading to learn: genre, knowledge and pedagogy in the Sydney school. Equinox.

[43] Salomon, G., \& Perkins, D. N. (1989). Rocky roads to transfer: Rethinking mechanisms of a neglected phenomenon. Educational Psychologist, 24, 2, 113-142. https://dx.doi.org/10.1207/s15326985ep2402 1

[44] Shrestha, P.N. (2017). Investigating the learning transfer of genre features and conceptual knowledge from an academic literacy course to business studies: Exploring the potential of dynamic assessment. Journal of English for Academic Purposes, 25, 1-17. https://doi.org/10.1016/j.jeap.2016.10.002

[45] Smit, D. W. (2004). The end of composition studies. Southern Illinois University Press.

[46] Snow, M. A. \& Brinton, D.M. (1988). Content-Based language instruction: Investigating the effectiveness of the adjunct model. TESOL Quarterly, 22, (4). https://doi.org/10.2307/3587256

[47] Spack, R. (2007). Guidelines: A cross-cultural reading/writing text. Cambridge University Press.

[48] Spack, R. (1988). Initiating students into the academic discourse community: How far should we go? TESOL Quarterly, $22,29-51$. https://doi.org/10.2307/3587060 
[49] Wingate, U. (2016). Academic literacy across the curriculum: Towards a collaborative instructional approach. Language Teaching, 1-16. https://doi:10.1017/S0261444816000264

[50] Zarei, G. R., \& Rahimi, A. (2014). Learning transfer in English for general academic purposes writing. SAGE Open, 4 (1). https://doi.org/10.1177/ 2158244013518925 